\title{
Pentagon Ju-Jitsu - reshaping the field of propaganda
}

\author{
Emma L Briant
}

University of Essex, UK

\begin{abstract}
This article presents qualitative research examining adaptation to global asymmetric threats and a modern media environment of US Government propaganda systems by planners following 9-II, which proceeded largely unhindered by public debate. It draws on interviews with US elite sources including foreign policy, defense and intelligence personnel and documentary sources to explore how dissent was contained. A 'merging' of Psychological Operations and Public Affairs has been identified as a point of concern elsewhere and is argued to have facilitated the extension of US hegemony. It will present an account of the struggles between 2005 and 2009 when planners sought to alter 'foreign' and 'domestic' audience targeting norms that emerged in an old-media system of sovereign states with more stable populations. It focuses on a key example of transformation: the pressing through of internet policy changes for military Psychological Operations and Public Affairs, against resistance. Policies were brought in to coordinate and overcome discordance in foreigndomestic messaging by Psychological Operations and Information Operations personnel. Viewed as operational necessity for Psychological Operations, these resulted in a 'terf war' with Public Affairs who constructed a defence using discourses of legitimacy and credibility with domestic audiences. This article will show how concerns raised by Public Affairs were met by the reduction of their planning role, until a culture change and new orthodoxy emerged. Challenges raised by evolving media demand a reappraisal of propaganda governance and governments must allow greater transparency for public debate, legal judgement and independent academic enquiry to occur.
\end{abstract}

\section{Keywords}

propaganda, information operations, psychological operations, public affairs, US Department of Defense, strategic communication, online propaganda

\section{Introduction}

Since 9/11, an explosion of the internet and accelerated forces of globalisation brought accompanying pressures and opportunities ${ }^{1}$ alike - for citizens, whistleblowers, private corporations,

\section{Corresponding author:}

Emma L Briant, Journalism in the Department of Literature, Film and Theatre, University of Essex, Wivenhoe Park, Colchester CO4 3SQ, UK.

Email: teflpolsoc@gmail.com 
various groups with violent or peaceful intent, and governments too. Early media rhetoric during the Iraq war often mobilised domestic US fear behind calls for military solutions and global and domestic intervention, and shaped reporting of escalating conflicts in the region and the resulting humanitarian crisis. The narrow US political discourse on global conflict's causes and solutions helped usher in military spending increases in the decade following 9/11 of ' 50 percent, adjusted for inflation' (National Priorities Project, 2015). This funded expansion of and developments in coercive elements of military action; new strategies for social control and stability arrangements; and new developments in governmental propaganda. These have become increasingly augmented by 'big data' and extended powers of surveillance, with private corporations profiting from an expanded role throughout. This article illuminates the power struggles that occurred within US defense, largely under the Bush Administration, in the context of counter-terrorism propaganda between those seeking to define how propaganda wars of the future would be fought. It examines important changes in practise and how traditional distinctions between propaganda for foreign audiences - Public Diplomacy and Psychological Operations (PSYOP) - and propaganda for the US public and international media - Public Affairs (PA) were renegotiated. The content of Public Affairs outputs, and any government sources that may be used by mainstream media are particularly important domestically due to an over-reliance of reporting on 'official' government sources and perspectives (Entman, 2004; Papacharissi and Oliveira, 2008: 71).

As we entered a period of internet expansion many US government planners began arguing for transformation of US Government propaganda strategy - doctrine and laws they saw as outdated (Briant, 2015). Others sought to retain elements of the status quo and a look back at their failure to retain dominance illuminates how extension of coordination occurred and came to be accepted. This is an essential backdrop for understanding how government bureaucracy advanced measures aimed at controlling the global online environment. Commercial companies further exploited their geographical flexibility, minimal accountability and 'black boxed' practises, to profit from this desire to side-step awkward bureaucracy designed to protect the public.

Traditional 'sub-fields' within propaganda differ due to many factors. These include: different legal authorities controlling funding; the influence of wider doctrine and objectives associated with the government agency; factors such as historical legacies, organisational cultures, a legacy of public (in)visibility, or proximity to other fields, such as degrees of engagement with PR, journalism, tech industries and other private sector relations. Traditional 'rules' were seen as obstructing effective propaganda at home and abroad. Practices became ultimately coordinated to ensure messages would not contradict, and to maintain strategic control of messages for different audiences online. But 'strategic communication' and the 'merging' of PSYOP and PA raised concern in academia and beyond (e.g. Briant, 2015; Gardiner, 2003; Miller, 2004; Snow and Taylor, 2006). Public Affairs Officers (PAOs) in the Pentagon saw threats to their credibility and sought to retain control of the process. This article engages in deep exploration of struggles between subfields of propaganda. It shows how PSYOP and Information Operations (IO) personnel ${ }^{2}$ struggled against Public Affairs over the adaptation of systems operating in concert for overall effect.

Of course propaganda long had murky ethics - little was impossible for the right agency, with approval from above, in the context of war. The US traditionally divided propaganda capabilities according to audience, sensitivity of operation, and extent of persuasion, with external propaganda permitting more aggressive persuasion (particularly where directed toward enemies), and belief in the 'fourth estate' allowing some scope for media debate domestically. One reason given is transparency and ensuring domestically (and between allies) that propaganda remains 'uncontaminated' by messages intended for the enemy. Traditionally then, military PSYOP - for foreign and enemy audiences was kept distinct from PA and Public Diplomacy (for foreign audiences) and changes in often long-habituated practises and associated rules were pushed through. ${ }^{3}$ Another, operational, 
reason underpins targeting: messages not tailored for a specific audience are widely considered less effective. The transformation in global media and global conflict presented operational reasons compelling practitioners to change audience targeting norms, putting these in tension with 'ethical' justifications more publicly emphasised.

It is crucially important to understand how changes in practise occur amid the rapid adaptation of modern propaganda systems. This article focuses on the struggles to reform systems once argued to be necessary for democracy but seen as 'outdated' by Psychological Operations personnel pressing through internet policy to coordinate different online propaganda and overcome messaging discordance. It presents new evidence of how concerns raised by Public Affairs were fought by PSYOP personnel, and ultimately marginalised. Private actors gained an ever greater utility. Wider public debate was resisted and largely confined to professional or industry forums.

Military PSYOP was 're-branded' in 2010, as a hybrid communication from Military Information Support Operations (MISO). MISO's increased similarity to Public Diplomacy reflects the broader role of Defense in a 'global counter-terrorism campaign', which expanded the range of Department of Defense (DOD) activities. ${ }^{4}$ Legislation was amended in 2012 to allow Public Diplomacy propaganda previously restricted domestically to be disseminated within the US (Smith-Mundt Act, 2012). Challenges such as the acceptable role for government and private sector as media technologies and associated threats and opportunities rapidly evolve, demand fuller transparency to enable the necessary reappraisal of propaganda governance.

\section{Methodology}

Much has been written on the cultural products and crucial relationship to public opinion. How propaganda is produced and political, cultural and economic pressures that shape its production are important; but informal aspects of planning (Briant, 2015) are rarely explored. The article draws on emails and interviews with 12 elite sources from the US including personnel working since $9 / 11$ in foreign policy, defence and intelligence. ${ }^{5}$ It builds on previous research in analysing this struggle. ${ }^{6}$ The article focuses on key figures involved in US propaganda during a period of contestation when the traditional distinctions between propaganda for foreign audiences Public Diplomacy and PSYOP - and propaganda for the US public and international media PA - were being challenged and reshaped (see Briant, 2015; Gardiner, 2003; Miller, 2004; Snow and Taylor, 2006). Access for interviews in this subject area can be difficult and some interviewees are more open than others, particularly where criticism is concerned. A minority of the interviewees required their quotes to be anonymised, some to approve some context; this limits later editing. ${ }^{7}$

\section{Fluid Propaganda Audiences}

The post-9/11 globalised, fluid media environment meant isolating audiences geographically and targeting them with different messages became difficult. Media flowing across borders resulted in contradiction, destroying credibility. As Former Chief of Staff to Secretary of State Colin Powell, Department of State (2002-2005) Lawrence Wilkerson said, the propaganda message 'can't be the same for the Indian Muslims, as it is for the Indonesian Muslims', and 'you can't send the same signals to the $1.5 \mathrm{bn}$ Muslims, as you're sending to your own people to Ra-Ra them up for the conflict' (23 June 2009, interview). The DOD recognised this, noting how covert PSYOP messages were increasingly entering the domestic media (30 October 2003). US Former National Security Council Director for Global Outreach, Kevin McCarty ${ }^{8}$ and others expressed a strong belief that the existing audience rules were outdated. He said 'every Department, Agency or Office including 
that of the President, have limitations around what they can and can't do. And none of them were written for the world we live in now' (13 March 2013, interview). ${ }^{9}$

This had implications for planning and public debate as DOD became concerned with adaptation and finding a solution for what was seen primarily as a coordination problem, not one of ethical practise. The internet era brought inconsistencies. Austin Branch, who played a lead role in shaping practice throughout this period, ${ }^{10}$ said 'we have to look at policies and procedures and communication ... rhythms that would allow us to deconflict and coordinate and ensure that we weren't committing information fratricide' (8 August 2015, interview). Traditional separation of PSYOP and PA was seen by many as a somewhat artificial division - evidence that its dominant purpose is the operational one not a normative 'strategy of truth' (Snow and Taylor, 2006). Loose distinctions between functions were renegotiated within defence to increase consistency between covert and overt PSYOP messages, PD and PA, and coordination was increasingly accepted as necessary to ensure a consistent campaign.

As misleading politicised evidence presented in the domestic context aimed to justify the invasion of Iraq - via Colin Powell's speech to the UN and the 'dodgy dossier' in the UK (Herring and Robinson, 2014; Schwartz, 2013), concerns were also raised early in Iraq about how propaganda in the military context was evolving. Retired US Air Force Colonel Sam Gardiner in 2003 said the US 'allowed strategic psychological operations to become part of public affairs' (8 October 2003). From 2004 to 2006, Deputy Chief of Staff for Strategic Effects and Coalition Iraq Spokesman, Gen. Caldwell, sought to change official IO doctrine to lessen 'boundaries' preventing coordination. From 2005 to 2009, amid instability in Iraq, IO spending rocketed from $\$ 9$ million to $\$ 580$ million (Vanden Brook, 2012). The article discusses the debates and planning, and a short timeline below gives further context:

$\underline{2001}$

September 11 - Attacks on United States

October 7 - Invasion of Afghanistan

October 26 - Patriot Act passed

October 30 - Office of Strategic Influence (OSI) created

$\underline{2002}$

February 19 - OSI exposed in media

February 26 - Rumsfeld declared closure of OSI

November 8 - UN Resolution 1441 adopted

$\underline{2003}$

January - April - Global anti-war protests

February 5 - Colin Powell speech to UN Security Council making case for war

March 20 - Invasion of Iraq: 'Shock and Awe' and embedding media

April 2 - Jessica Lynch dramatic 'rescue' media spectacle shaped by Public Affairs statements (Loeb and Schmidt, 2003

April 6 - US Marine Corps arrive in Baghdad

April 9 - US Marine Corps place a US flag on Saddam Hussein statue, remove, then stage manage Iraqis pulling statue down (NPR, 2008) 
October - 'Information Operations Roadmap' (Department of Defense, 2003)

December 13 - Hussein captured

$\underline{2004}$

March-April - First Battle of Fallujah

May - Abu Ghraib images of abuse emerge

November 7-December 23 - Second Battle of Fallujah - massive casualties

$\underline{2005}$

January 2 - Iraqi elections

April - CIA: Hunt for WMDs exhausted

November-December - Media reveal US Army paid Iraqi journalists to publish propaganda

$\underline{2007}$

January - 'The Surge' announced - 20,000 American troops deployed

'Fusion Cell' established in National Security Council targeting thought-leaders (Briant, 2015)

June-August - New DOD internet policies

July 12 - Baghdad Airstrike - Iraqi civilians and two Reuters journalists killed

$\underline{2008}$

September 11 - Joint Special Operations Command Cyberwarfare section shuts down websites identified as jihadist en masse.

$\underline{2009}$

January 20 - Barack Obama assumes office

$\underline{2010}$

MISO adopted

April 5 - Wikileaks released Collatoral Murder video showing 2007 Baghdad airstrike - Manning arrested under Espionage Act

\section{The Impasse}

As IO funding soared under President Bush, in the Pentagon, a power struggle between PSYOP and Public Affairs aimed to shape the future of propaganda, and peaked between 2005 and 2009. Austin Branch called it 'very, very painful' but said the debate 'was absolutely necessary to build the foundations of a policy that would shape how we operate in the information environment in the future' ( 8 August 2015, interview). The internet and digital technologies challenged the way propaganda was handled. But some in Public Affairs defended traditional divisions they saw as protecting their credibility. Some, like Former US Navy Chief of Information and Former US Special Assistant to the Chairman of the Joint Chiefs of Staff, Rear Adm. McCreary, ${ }^{11}$ felt they didn't want to be 'tainted'. He was critical of changes taking place and felt MISO 'clearly is' encroachment of PSYOP into Public Affairs:

What you've created with [MISO] is they believe their effort is to go into foreign audiences and convince everybody that only the United States' way is right ... There is no such thing as strategic PSYOP, PSYOP is an operational function, and it was originally designed to convince people to do or not do something on 
the battlefield to give you operational advantage. And well they say that's what we're trying to do but at the strategic level ... They're trying to define the ... battlespace as the globe and everything's a battle. (15 October 2013, interview)

Rear Adm. Frank Thorp ${ }^{12}$ succeeded McCreary in key PA roles and both were vocal in the impasse with PSYOP.

\section{Early Contestations}

Some pointed to history of the much-criticised 'War on Terror' Office of Strategic Influence (OSI) - a 2001-2002 attempt to lead propaganda - as a primary reason for this opposition to newer IO-led changes. Austin Branch said personnel at,

OSI office ... were really not professional communicators who didn't understand ... this strategic information environment, [or] the implications ... of some of the things [they were] thinking about doing from a policy, ... authority, ... public perception standpoint. You can understand why the public affairs guys got nervous and they stayed nervous. (8 August 2015, interview)

Branch pointed out that DOD failed to get the advice of Public Affairs in setting up OSI. As the Information Operations field was still developing, and training and experience early on was 'kind of iffy', the OSI was staffed by 'amateurs' not 'understanding of the nuances of the ramifications of their actions' (8 August 2015, interview). By contrast, he said 'public affairs guys were ... engineered to be reactors; they weren't planners, they weren't strategists' like IO who were trying 'to actively shape the information environment' (8 August 2015, interview). But Public Affairs' exclusion led to some animosity and suspicion.

A need for change and 'coordination' of some sort, was, by 2005, accepted by PAOs too - at this time the nature of coordination was disputed. The exposure of contractor Lincoln Group's covertly planting of articles in Iraqi and Arab media led some to feel concerned that such activities undermined trust, harming US strategic objectives and the credibility of independent Arab media. Articles were American-made, and failing to pass as 'genuine' content. Lincoln Group had no background in public relations or the media. But they were also supervised and approved by the Army; the activity itself was not, in fact, unusual activity for PSYOP, 'We don't want somebody to look at the product and see the U.S. government and tune out,' said Col. James Treadwell (Gerth, 2005). The media reaction increased Public Affairs' concern over their coordination with Psychological Operations, and risks of PSYOP outputs damaging the credibility of Public Affairs. Thorp said 'the Public Affairs folks saw what the psychological operations folks were doing on the Pew Research Center (2009) Press Accuracy Rating Hits Two Decade Low: www.people-press. org/2009/09/13/press-accuracy-rating-hits-two-decade-low/ battlefield in Iraq'[AQ: 2] and formed the 'perception that, hey - they're saying one thing, the Public Affairs people are saying another thing and the United States is looking pretty silly' (24 August 2009, interview).

When the expansion and lack of accountability of IO received criticism, the industry dug in its heels, critical journalists at USA Today were targeted with harassment by the owner of contractor Leonie, Camille Chidiac, via an online campaign (Vanden Brook, 2013a). There was distrust and concern that PAOs might be facilitating media criticism. One Anonymous Information Operations Officer claimed of OSI: 'the folks at OSD(PA) did a smear campaign on them', namely 'Victoria Clarke'; and he asserted this happened again: 'we were looking who might have leaked the insider story to the USA Today reporters' ( $25^{\mathrm{h}}$ July 2013 , email). ${ }^{13}$ Public affairs personnel reject flatly any claims of leaking, but it seems widely believed within the IO community. Clarke objected to OSI 
but expressed little knowledge of terf-war conflicts, saying coordination 'worked pretty well' during her time (2015: 55).

But according to Branch,

in the earlier days ... there was a great reluctance to share some information with public affairs ... a lot of it was very classified and there was a concern [among IO personnel that] classified information ... would be put at risk when given to the public affairs guys because they didn't like IO. Sometimes it would be exposed to media or other folks ... in ways that were unhelpful to IO. (8 August 2015, interview)

Branch gave an example,

in 2004 the web operations ... somehow it got in the hands of the media and it ... was framed in an unhelpful way ... it didn't need to happen that way. There was spin and there was concern from the public affairs community that we could have had a discussion about it and ... worked it ... it was unnecessary and unhelpful to have that debate in a public space. (8 August 2015, interview)

Public Affairs were sometimes accused of following political motivations. Due to his closeness to Bush, some journalists saw Former Assistant Secretary of Defense (ASD) for Public Affairs Dorrance Smith's role in reality as political - preoccupied with defending the White House and he was seen as uncooperative. One reporter quoted in 'Harpers' contrasted this with press relations of predecessors Torie Clarke and Larry De Rita: 'you could go to them for help and for information. We see the cleaning lady more than Dorrance' (Silverstein, 2007). Smith adopted a hostile stance on Al Jazeera calling them 'The Enemy on our Airways' (US Senate, 2006). High-level disagreements between PSYOP and PA could have a ripple-down effect as systems were bypassed to push ideas forward. Briant quotes McCreary (2015: 151) saying:

The problem was when people tried to run up programs on their own side and get it to the boss and not do the coordination ... and all of a sudden you're [finding you contradicted someone else] and, by the way, it's the truth and what [they're] trying to propose, it's not so much, or not as transparent. The problem was when it went up your own chain and it wasn't shared with the other side, it was primarily done because you knew the other side would disagree with it. And so you probably shouldn't have taken it up to begin with!

Branch explained how 'effectiveness' or proof of 'return on investment' became an 'Achilles heel' and was concerned with how it could be used as leverage by people criticising propaganda:

[I]f you're constantly changing people, and the programmes are having to be redone based on the new then you don't have that consistency or persistency necessary to get the feedback over a year, year and a half, two years about a programme. Because you know people don't change attitudes or behaviours overnight - unless you're an American [domestic] audience; people change in milliseconds. (8 August 2015, interview)

In assessing 'the information environment' Branch said 'there's three-dimensional checks, this is very complex and things happen at near real-time speeds ... and sometimes it's gotten away from us'. He further clarified, 'Have there been times where planners didn't think completely about the second or third order effects? Yes. And as a result have learned some hard lessons.' But he stressed this is 'a challenge, but that's not unique to information operations' (Branch, 8 August 2015, interview). To resist the impression of propaganda having little value or unpredictable effects, a large industry of contractors flourished on 'proving' this value. 


\section{Coordination Attempts}

In 2005, Thorp sought to facilitate coordination, recognising audiences can conflict; he sought a Public Affairs-friendly coordination. He regarded total separation as counterproductive but felt PA should lead the message. McCreary thought the coordination needed to be in the 'staffwork' ensuring Public Affairs are consulted and 'read in' on PSYOP campaigns (15 October 2013, interview). Thorp said he authored the first doctrine to reshape American propaganda into the 'Strategic Communication' approach (Deputy Sec. of Defense, 2006). But many thought Thorp was obstructive to PSYOP.

Some interviewees said that Thorp's 'doctrine' reflected the fact he was 'a hard-core Public Affairs person'. His approach according to Matt Armstrong, ${ }^{14}$ reflected a view that 'public affairs is the centre of the universe and everything else is mischievous, and full of lies and obfuscations' (6 March 2013, interview). Public Affairs' effort to direct the change was opposed by PSYOP personnel including Col. 'Glenn' Ayers. ${ }^{15}$ Some could be derisive and Ayers mocked what he saw as Public Affairs' inability to engage with in-theatre audiences and cultures:

if you don't understand I'm gonna talk to you louder in English ... just so I can and get out the public affairs note. (17 May 2013, interview)

Thorp was key spokesman on the Jessica Lynch story, criticised in the media as an example of Iraq war misinformation aimed at domestic morale (see: House of Representatives Report, 2008). But McCreary saw the attitude Ayers expressed as 'fairly cultural' in the army who failed to see communication beyond PSYOP terms:

operationally-focussed and really doesn't put the premium on public affairs ... I think that's because many of them grew up with PSYOP and they just don't understand the communication environment as well as they should. (15 October 2013, interview)

Dorrance Smith ${ }^{16}$ also said coordination that goes beyond 'sanction' by, or check and approval by, Public Affairs was potentially problematic:

be careful what you wish for because you then become complicit in whatever it is ... and so how do you then have deniability? Or how do you then have credibility? When it then goes awry or becomes public and then you have to then go out and defend it ... internally that might be brilliant ... in terms of long-term relationship, I'm not sure that it's all that wise ... Public Affairs is not PSYOP and once you go down ... you have to be very careful about when people were ... convincing you that it's in your best interests for them to deceive people for whatever reason and use the media as part of their deception, I just have no comfort in that. (10 September 2013, interview)

When Ayers mocked PAO's as ill-equipped for communicating with foreign audiences, he had a point. Separation of foreign and domestic has been counter-productive in many ways in how it divides the US from and defines its relationship with the international community. And from 'democracy-building' abroad to CVE efforts at home US propaganda communicates a sustained gulf of understanding of non-western cultures and Islamophobic double-standard as white nationalist discourses and violence (e.g. Esposito, 2011) have been ignored.

Of course, PA is also selective, presenting information in such a way that it promotes US Government perspectives. Armstrong pointed out that PAOs don't just 'throw unadulterated information over the wall'. Thorp's approach, according to Armstrong, is 'I inform, I do not influence. ... It is the general PA doctrine'. He said, though the word is never applied, PA actually does 'influence' people: 
ok you're the public affairs officer for Fort Bragg. The main gate is going to close for construction ... So you're actually going to suggest alternative routes ... why are you doing that? You're doing that because you wanna show the community that the army cares ... and by the way did you realise you're changing their behaviour? Not only that, not just influence, but you're changing their behaviour! 'Changing behaviour' was one of the key components of PSYOP. (Armstrong, 6 March 2013, interview)

Thorp insisted that for an information campaign to be strategically coordinated, there needs to be 'one set of rules' and it is necessary to decide 'whether the Public Affairs rules are right, the Psychological Operations rules are right or we need a new set of rules' for guiding propaganda (24 August 2009, interview).

\section{Pentagon Ju-Jitsu}

Commanding General of the Combined Arms Centre (2005-2007) Petraeus transformed the structures responsible for the 'information' sphere, continuing once he took over Central Command in 2008. But disagreement persisted, holding DOD policy on internet activities back until 2007. Internet activities were governed by PSYOP regulations - legislated at a time before the internet was anticipated. Ayers said that, when he was Psychological Operations Division Chief, 'we got the Deputy Secretary of Defence to sign' two new policies - the Trans-Regional Web Initiative (TRWI - later, Regional Web Initiative Program) and Interactive Internet Activities (IIA) policy and 'pushed those through' (17 May 2013, interview). ${ }^{17}$

The form the policies took served to further blur the functions of PSYOP personnel and PAOs (Silverberg and Heimann, 2009). Ayers, along with other interviewees, saw Thorp and McCreary as responsible for preventing 'progress' with this:

There was more than reluctance [to coordinate Psychological Operations with Public Affairs], there was actual stonewalling, and physical, bureaucratic ju-jitsu to make sure that Psychological Operations authorities were not done. (Ayers, 17 May 2013, interview).

The IIA policy Ayers applies to online Public Affairs activities and 'programs, products and actions that shape emotions, motives, reasoning, and behaviours of selected foreign entities' (Deputy Sec. of Defense, 2007a) . Silverberg and Heimann argued it 'might be viewed as fusing PSYOP and Public Affairs into a generic communication effort', since it applies to both PSYOP personnel and PAOs and does not specify different activities (2009: 82). PA activities were included in a similar definition to PSYOP, the only difference being the words 'shape' and 'influence'. PAOs are stated to target media, but their activities are not distinguished from PSYOP. The term 'shape' is undefined and open to interpretation. Silverberg and Heimann state it 'establishes a hybrid PSYOP-Public Affairs model' (2009: 86) and steps into State Department territory - PD.

There is a requirement for IIA to be 'true in fact and intent' but while 'attribution' is specified, there is broad scope for the Commander to navigate this due to 'operational considerations' (Deputy Sec. of Defense, 2007a; Silverberg and Heimann, 2009: 85-86). This was a point of contest for PAOs, Ayers said, viewing it as a terf-war:

that was the first time ... in that document, that we had articulated the different types of attribution and who could use them. And specifically it says in there that PA can only work in the realm of attributable information. Psychological Operations could work in all three of them. PA does not like that. ${ }^{18}$

This was because it excluded PA from influencing PSYOP messaging, which they feared would re-enter the country and be seen by a domestic audience - their area of concern. 
Externally messaging is also likely to be undermined by wider military action. From Ayers' perspective:

They want to have control of information 'cause when it blows up in their faces, and they're standing on a podium, they look at it from that standpoint. 'How am I going to spin this when it comes out?' (17 May 2013, interview)

Ayers described putting pressure on Thorp, to pass TRWI, IIA and delegation to '0-6's' - lower ranking personnel outside the Pentagon:

He specifically sat on those packets and would not either approve them or disapprove them, for months. Until ... I had to get ... my one-star Air Force boss to go in and sit down with Frank Thorp, in his office, and read through the entire message about TRWI ... And he kept on saying things like, [whiney voice] 'I don't understand this' ... my IO force boss, said ... this great thing. He looked across the table at him ... one-star to one-star and said, 'You did go to university right? What about this message is not apparent to you, that you don't understand? Frank.'

Ayers used influential networks to press changes through and navigate resistance from PA:

Well, here's how I got it through. I always punched above my weight as a full Colonel in the Pentagon, so I got my three-star boss, I got the Director of the Joint Staff, who was another three-star ... I got a couple of ... Senior Executive of Services within USDI [Under Secretary for Intelligence] within policy, to ... help me push this through ... Because ... my first assignment at the Pentagon was ... Military Assistant for Secretary Rumsfeld and for Secretary Wolfowitz. So I went for a year to the War college and I came back in, and I still knew all the networks at the Pentagon. I was friendly with quite a few high people, so ... I used my powers do that. Those three things that I pushed through ... it was the IIA, TRWI and the 0-6 thing and every single one of those I had to use the Pentagon Ju-jitsu and get around public affairs. Public Affairs was the key impediment to everything we tried to do, because once again going back to what I said Emma, they look upon all information as in the realm of Public Affairs information ... but Psychological Operations uses the same information. But we only may choose to use ... $80 \%$ of it ... to modify the behaviour of a target audience. Public Affairs thinks everything needs to be totally open, everything needs to be spoken about, everything needs to be ... attributed. Not the case. (17 May 2013, interview)

One solution Ayers stated was to cut the Assistant Secretary of Defense for Public Affairs and Under Secretary to the Defence for Policy and Special Operations in the Pentagon out of approval, which would give them greater liberty to make the change. Here Thorp describes cultural differences between the subfields:

There were folks in the psychological operations world could not understand why in a million years we would talk about ... for instance investigations ... the whole Abu Ghraib thing. There were those who said 'why should we even talk about that publicly?' - Because if we talk about it the enemy will take advantage of it. Well that's true, but the issue is not not to talk about it the issue is not to do it. It will become public one way or another. (Thorp, 24 August 2009, interview; emphasis added)

\section{Delegating Out}

Public Affairs' concerns clashed with the PSYOP planners' policy to increase their freedom to manoeuvre using online and digital media. One change implemented was that in the internet policies, 'contrary to two decades of practise, [a] delegation empowers commanders to conduct information operations at their discretion' where 'previously they had to have senior-level Departmental 
approval' (Silverberg and Heimann, 2009: 82). Significantly Ayers pushed the PSYOP approval process outside the Pentagon; he said:

Those Commanders ... in the area ... knew the environment better than anybody else ... so if they had ... an [Non-Commissioned Officer], school-trained ... from a PSYOP unit ... or an Officer, and it worked through the proper procedures, they could approve at an 0-6 level [that of Naval Captains or Colonels in the other services]. (17 May 2013, interview)

Ayers' planned to change authorities for PSYOP to permit approval by lower-level officers, this meant that:

if you had, a, PSYOP-trained NCO on your staff, or an Officer ... you could do tactical level [PSYOP] products, without getting higher approval... prior to that, [approval] was all the way at a 2-star or 3-star level. (17 May 2013, interview)

Ayers said:

what I said is if you're gonna put out a, a leaflet or a handbill, in Arabic that says, 'dont crap in the water and drink it', you don't need a 2 star General to sign off on that! Ok? (17 May 2013, interview)

This suggests PSYOP is used for seemingly-trivial 'public information' purposes -messages support a variety of objectives and some may or may not be attributable or truthful.

Ayers sought to remove Pentagon Public Affairs from planning, increasing PSYOP's autonomy, because:

At the beginning of the conflict, we ... actually had to get ... all of our products that we were dropping over Afghanistan, approved by the [Assistant Secretary of Defence (ASD) for] Public Affairs and by the Under Secretary of Defence for Policy and Special Operations. We had people looking at our leaflets in DC ... this was back in 2001 and saying, 'this word is spelled wrong, or you have a comma in the wrong place' - it's because we had to send it to them in English!

He got tactical PSYOP approval transferred to personnel ranking as low as 'PSYOP-Trained NCO' in theatre, when he was Joint Staff J-39 Deputy Director Global Operations, and:

out of the Pentagon, so I could get 'em away from Frank Thorp. And I could get him away from Policy.

This strategy deliberately cut chain-of-command oversight to give greater autonomy in theatre:

We were being second guessed ... and 'what if...' and all this other kind of stuff by people who had no clue sitting in DC. So I took it upon myself when I came in on Joint Staff, that approval was gonna get out of ... the Pentagon. (Ayers, 17 May 2013, interview)

But this change removes a layer of checks, reducing oversight and accountability, for the purpose of excluding PAOs from protesting PSYOP they thought was problematic.

Branch stressed the importance of training - that proportionality of second and third order effects on a population were weighed, sometimes concluding 'the risk is too great' (8 August 2015, interview). ${ }^{19}$ But Branch stated that now if planners 'think that there is going to be a second or third level effect at someone else's space they have to figure a way to coordinate that'. And also 'the more folks that have equity in it, the more challenging it is to conduct operations ... that involve activities in the information space' (8 August 2015, interview). 
Dorrance Smith during 2006-2009 was Assistant Secretary of Defense for Public Affairs, and recalled some of these discussions from his time in office. He explained why it was important that 'front office' approval was gained:

I pretty much was an advocate of Public Affairs being open and transparent in everything it did ... I think that my position was consistent with the people who went before me like Torie Clarke and Larry De Rita ... I think it's the role of [ASD Public Affairs] to be open and transparent and you can't have your foot in all of the various ... there's certain areas where, as Public Affairs, you really shouldn't be involved in the planning, the execution, the process ... I can't really remember a ... big conflict between what I was doing in Public Affairs and what some military operation was involved in. There were times where there would be these policy discussions and ... the PSYOP people or the people who were in Special Ops would try to inculcate in doctrine or in policy that they could basically operate, you know, alone by themselves and without any transparency and of course Public Affairs would object to the extent that, that's where you get in trouble is where you do these 'off the shelf' operations that no-one knows about and hasn't had anybody in the front office sanction and approve it and then when the press find out about it the first- they don't go to the PSYOP people for a comment, they come to my office for a comment. I think a general example, there were times in policy discussions where a General would try to argue a certain point of view to the Secretary in order to try and make it doctrine or make it policy and I would ... as Head of Public Affairs we would 'non-concur'. (10 September 2013, interview)

Smith said 'I never felt that Secretary Rumsfeld ever put the Office of Public Affairs or me personally in a position that would've compromised our ability to do our jobs' he said 'whether or not [Rumsfeld] satisfied the itches of the PSYOP community' he wasn't sure (10 September 2013, interview).

But despite Public Affairs' claims to have 'non-concurred' on such attempts, policies delegating PSYOP approval out of the 'front office' were evidently passed. PA's arguments and ability to counter were structurally sidelined as authorities were processed, the operational imperatives had institutional priority over normative elements of PA organisational culture.

\section{Coordination}

This all happened during a period of wider media hostility to Rumsfeld which also had an impact on Public Affairs. US Former Assistant Secretary of Defense for Public Affairs Doug Wilson (who did not serve at the Pentagon during the Bush Administration) observed that as a result of this hostility, Pentagon Public Affairs Office was gradually marginalised, and until 2008 or even later, 'most of the war-related communication that was done out of the Pentagon was done out of information operations' (10 May 2013, interview). Some of Silverberg and Heimann's concern over changing practise was also felt by PA officials from this later period. ${ }^{10}$ [AQ: 6] Wilson, for example, criticised the de facto blending of PSYOP and Public Diplomacy. He said that in Defense, 'This middle kind of plant that grew up ... some called it MISO, some called it Strategic Communications' - it was 'this middle area that caused everybody such heartburn.' For him, it was 'a glaring example of how little on the non-military side of public diplomacy was working effectively’ (10 May 2013, interview).

Since Frank Thorp retired as Deputy Assistant Secretary of Defense (Joint Communication) in 2009, there has also been less opposition to coordinating PA with the other tools. As Armstrong put it, 'what was starting the revolution in there [was that] you had Rosa Brooks over in policy, and Doug Wilson in PA, and Austin Branch at IO. You had three very competent, respected people who got along very well ... and you did not have Frank Thorp in there anymore' (6 March 2013, interview). Wilson came in to the Pentagon as ASD for Public Affairs in 2009 and had a different 
approach to coordination. He described this change, 'I never thought Information Operations was a bad word. I wanted to defuse the tensions between the Public Affairs and the Information Operations shops. My approach has always been that communications is a broad spectrum, from the overt to the covert, and it's a matter of using the tools in tandem.' He observed that some in the Public Affairs branch 'thought that if you dealt with the dark side of communications, you were getting your hands sullied. I think that's the result of spending too much time carving up the field into stovepipes.' Wilson said, 'I brought with me a desire to develop a holistic communications team. And not feeling that Austin Branch was, you know, from Planet Mars' (10 May 2013, interview). It was suggested that it was 2009 before Public Affairs were able to 'get around the planning table' again:

During my tenure, some under Gates, but particularly under [Leon] Panetta, Public Affairs started to regain its seat at the table as the place that developed and coordinated communication strategy for the Pentagon. (Wilson, 10 May 2013, interview)

This impacted Wilson's approach when 'point person for communication on Wikileaks in the Pentagon' coordinating internationally, cross-governmentally and of course, between Public Affairs and Information Operations capabilities:

We met with the New York Times, we were able to go through [the documents in question]. We couldn't prevent the publication but we were able to work with them in terms of identifying things that truly would put lives at risk. There was tremendous cooperation between the military and intelligence communities, great cooperation between the United States and Foreign Governments ... communicating in advance things that could be embarrassing, and things that could be a national security risk. And when it came to ... between me and [Senior Advisor, then Director of Information Operations] Austin Branch, I mean he certainly was aware of and part of the discussions about how we were going to be handling it. (Wilson, 14 May 2013, interview quoted in Briant, 2015: 161)

Eventually, the systems and cultures of Public Affairs at DOD changed in response to pressure:

for a long time in the period you're looking in, PA was viewed as the white horse and everything else was dark and simply being in the same room tainted PA and so they couldn't even be there. But you have that concept breaking down at the personal level. You have some folks in the field working very well together and properly integrating the activities. (Armstrong, 6 March 2013, interview)

Armstrong gave an example of where he saw Information Operations take the lead,

this senior officer ... was IO, and smart, and the junior officer was PA, and the PA deferred to the IO guy $\ldots$ and he led the initiative. He was essentially in charge of the communication synchronisation.

But he confirmed that this could be inconsistent and depended on the initiative of the Commander, it 'really varied' and sometimes,

you had the ... commanding officer ... only wanting his PA person in the room and figured IO was something to be brought in later and sprinkled onto a project.

This was seen as a problem because, 'Of course the PA guy's not thinking locally [in theatre], the PA guy is thinking back in US primarily to the US public, congress and the Pentagon - the $I O$ guy tends to be focused locally and regionally' (Matt Armstrong, 6 March 2013, interview; emphasis in 
original). Former Director of the Joint PSYOP Support Element and Commander of 4th Psychological Operations Group in Iraq (2003) Col Jim Treadwell stated that:

From my vantage point it appears that most PA officers working in the field are more focused on supporting their operational commanders than they were 20 years ago. By that I mean they are still informing the public, but they are doing so understanding that the information they provide will have an influence. Perhaps you could say they are informing with a purpose. (6 May 2013, email)

Public Affairs had transformed, its potential for 'influence' and more 'purposeful' communications recognised. Yet TRWI websites continued to be criticised for poor coordination with State Department efforts (Vanden Brook, 2013b).

\section{Contracting}

Others with 'equity' in the information space include PR companies acting as contractors in information activities. With the difficulty in transitioning the bureaucracy and the resistance and concern over changes in doctrine to unite these efforts, private contracting became the easiest way to extend fluidity between different information activities. Targeting of friendly audiences extended this wa[AQ: 7]. One senior employee at a large contractor who worked across the spectrum of different activities with both the DoD and State Department stated that 'the US military distinguishes between PSYOP/IO and military deception so there are technically rules against deception by PSYOP personnel because deception is classed as a different activity - permitted in a conflict situation. But if you're a contractor you work out of a private office and you don't have to follow the same chain of command. If you want to do it, you can put it out' (28 September 2017).

Targeting of friendly audiences was also facilitated as it

doesn't raise suspicion in a foreign, friendly country to have a 'market research and marketing' company set up an office there and start work. You can be open about its existence. If you were doing something with a military unit you need to declare it to the country. So it's easier to be covert because the company can be overt about its existence but not declare what it's doing. Contractors are most useful for PSYOP in countries that are friendly and neutral, not conflict zones, to enhance your objectives there when you want to meddle but don't want to actually 'invade'. (Senior Employee at Large Contractor, 28 September 2017, interview)

Anxiety about damage to PA's credibility may have reduced if PSYOP output is unattributable, disseminated by a less conspicuous PR company.

This interviewee also said "contracting allows more liberty with persuasive messaging targeting the home audience; the same people are producing PSYOP as producing the Public Diplomacy products and even for Public Affairs - the only difference becomes attribution, whether or not you're including a little logo in the final product before you put it out. The actual content or the persuasive nature and message of the output is often the same and moving it outside government bureaucracy has helped to facilitate that' (28 September 2017, interview).

\section{Whose 'Information Space' Is It Anyway?}

The Pentagon's Iraq propaganda war involved a cultural struggle; not just with the Iraqi audience, the international community or the American public, but also over the future of propaganda. With planners militaristic focus on 'deconfliction' there is assumed legitimacy of dividing the 'information space' in its entirety (domestic and foreign) into occupied territory for propaganda streams 
who have 'equity' over managing it - personnel must consider effects of treading on toes in 'someone else's space' (i.e. territory worked in or occupied by other government personnel or projects). As we moved toward the era of 'big data' analytics using PR companies with 'black boxed' methods and little transparency this concern is heightened. Increasingly of course the same media corporations enabled by successive policy to build monopolistic commercial surveillance and persuasion platforms (Crain and Nadler, 2017) are empowered and compelled to regulate this information space, amid concern over 'fake news'. As myriad actors grapple to dominate amid complex informational 'threats', audiences lose autonomy in their legitimate claim over this space as vulnerabilities are exploited among young and old. Whether domestic or foreign when seen as 'information terrain' or operational 'battlespace', people are not sufficiently considered as also actors holding 'equity' in the information environment of their own minds. ${ }^{20}$

Struggles such as those detailed above illuminate the tensions in the relationships both with journalism (as their reliance on public affairs and protection of sources was viewed as offering PAOs potential strategic advantage in fighting internal battles); and the public (who rely on a media - demarcated as the 'battlespace' for propaganda - to inform their opinion - including about their governments' propaganda activities). Certain basic knowledge of process is necessary to consider propaganda that might reach a domestic audience 'consensual' and consistent with democracy. The 'ju-jitsu' was seen as 'resolved' in the field but public debate was limited. When criticism from Public Affairs and the State Department was vocalised, IO was gaining power and their fear of PAO's closeness to the media was potentially threatening, whether baseless or not, shaped practise greatly. It impacted the role and power of PA in shaping external communications policy.

Different interests, subcultures and priorities across the subfields of propaganda were presented as a 'problem' for the coordination driven by a discourse of external imperative that we see driving demands for bot armies today. Forced transparency and dependence on social media are increasingly being exploited in dynamic 'bot wars' and 'computational propaganda' (Woolley and Howard, 2017) between the West and its enemies. The period discussed heralded a marked decline in US trust (Pew Research Center, 13 September 2009) in mainstream media reporting that continues today. Protection of independent journalism and oversight of private contractors wielding algorithmic warfare have never been more important.

The debates detailed here laid a foundation for future elasticity and extension of activities we see today and raise questions about how the US will deploy new interventions to deal with 'fake news'. Differentiated 'rules' and practises were negotiated to manage and maintain the established order and control the information space as foreign policy failures unfolded in Iraq and beyond. Some personnel sought to challenge or resist the changes. Contradictions were resolved institutionally, prioritising operational imperatives.

For accountability, governments have to communicate. But at very least, the rules governing propaganda use should, in a democratic society, be transparent and subject to external enquiry. Whether or not the population supports different forms of propaganda use, how it is regulated, and the changing rules governing it (when, how, if and where it is used) must be debated. This example evidences how internal balances of power determine such changes. Only transparency and openness to critical social science and journalistic enquiry can ensure planning and policy changes are genuinely in the public interest.

\section{Acknowledgements}

I would like to express gratitude to all interviewees who participated in this research. I also acknowledge here the assistance of my Research Assistants, and thank Elizabeth Balderston and Keirstan Pawson who provided valuable help with transcription of interviews. I would also like to acknowledge the support of the ESRC studentship that supported my doctoral research some of which this article draws on. I also am grateful for 
valuable feedback and suggestions from colleagues at the School of Media and Public Affairs at George Washington University as their insightful comments were instrumental in my final edits.

\section{Funding}

This research received no specific grant from any funding agency in the public, commercial, or not-for-profit sectors.

\section{Notes}

1. Including media convergence, online leaks and cyber attacks, hyper-transparency and mass-surveillance.

2. Information Operations is the integrated employment of different capabilities including Psychological Operations, Electronic Warfare, Computer Network Operations, Military Deception and Operational Security. Some personnel interviewed within this article are IO personnel or referred to this rather than just PSYOP. Terms used in the field can be confusing and should not be used as analytic categories, but these are necessary to identify different actors. Wherever possible to aid the reader I use the label 'PSYOP', but leave 'IO' where it occurs in direct quotes, titles or where the designation is important.

3. I discuss formal and informal 'rules' that comprise the cultures at greater length in Propaganda and Counter-terrorism (Briant, 2015). Snow and Taylor called it a 'democratic propaganda model' (2006: 390) has been far from democratic and other authors have pointed to the weakness of such claims (e.g. Miller and Sabir, 2012) or demonstrated harsh realities underpinning power and persuasion during 20th century conflicts (including Bacevich, 2006; Dorril, 2002; French, 2012; Herman and Chomsky, 2008; Weiner, 2008).[AQ: 8]

4. Consolidation in 1999 of the USIA into the State Department was partly to end the appearance of a centralised 'propaganda organisation'. Yet investment in capabilities at the Pentagon became so great as to dwarf other efforts.

5. With gratitude to research assistants Elizabeth Balderston and Keirstan Pawson for assistance with transcription.

6. The article analyses interview data, some of which is previously published in Briant (2015) alongside new previously unavailable interview data including Austin Branch who held a key IO position during these events. This allows new insight into the existing data.

7. In four cases interviewees required to see quotes from their interviews in context. In such cases the method was to show them a brief amount of text within which the quote was situated to gain their approval for the use of quotations. Attempts to walk back meaning were resisted and any alterations to the quotes and surrounding text were for reasons of accuracy and clarity only.

8. Also former US Naval Officer, Intelligence Officer, NSC and currently a Commercial Communications Consultant.

9. These laws and guidelines are discussed more fully in Briant (2015).

10. US Army Director of IO, Space and Strategic Communications (2002-2006) and Department of Defence Senior Advisor in Information Operations (2008-2010).

11. McCreary was also Former Director of Strategic Communication for the National Counterterrorism Center.

12. Thorp held positions as Former Special Assistant for Public Affairs, Former First Deputy Assistant Secretary of Defense (Joint Communication) and US Navy Chief of Information (Retired).

13. See Bakir (2013) and Hastedt (2005) on role of strategic leaking to further a specific agenda-builder's strategic aims. Using Hastedt's, analysis, were these contested allegations confirmed, this type of unofficial leaking during contestation would be 'warring' or 'entrepreneurial' - used to wear down opponents and block policy (2005: 419-421).

14. Member of US Broadcasting Board of Governors, Former Executive Director of the Advisory Commission on Public Diplomacy (28 March 2011-December 2011).

15. Col. Ayers was Commanding Officer, 9th Psychological Operations Battalion (Airborne) (2001-2003), Psychological Operations Division Chief, Joint Staff (2006-2008), Assistant to Secretary Donald Rumsfeld and Deputy Secretary of Defense Paul Wolfowitz (2003-2005), Contractor SAIC (2008-2012). 
16. Also Former Senior Media adviser to Coalition Provisional Authority, Baghdad.

17. The regulations were the 'Policy for DOD Interactive Internet Activities' (IIA) which enabled two-way communications using blogs, emailing, chat-rooms etc. (Deputy Sec. of Defense, 2007a), and 'Policy for Combatant Command Websites Tailored to Foreign Audiences' (only non-interactive websites) (Deputy Sec. of Defense, 2007b).

18. $100 \%$ non-attributable military IIA can be authorised by the Defense Secretary, though this is rare as 'there are other people who do that' kind of activity (Ayers, 17 May 2003, interview).

19. Other accounts show this wasn't true of everyone (Briant, 2015: 46).

20. And it is necessary to remember the 'colonisation' of different parts of this 'information space' may of course also be underpinned by differentials in incentivisation, physical coercion or force in the physical 'terrain' (Bakir et al., forthcoming).

\section{References}

Bacevich A (2006) The New American Militarism: How Americans Are Seduced by War. Oxford: Oxford University Press.

Bakir V (2013) Torture, Intelligence and Sousveillance in the War on Terror: Agenda-Building Struggles. Farnham: Ashgate.

Bakir V, Herring E, Miller D et al. (forthcoming) Rethinking propaganda as a subset of organised persuasive communication. Working paper.

Briant EL (2015) Propaganda and Counter-terrorism: Strategies for Global Change. Manchester: Manchester University Press.

Crain M and Nadler A (2017) Commercial Surveillance State. $n+1$ Mag. Available (accessed 1 October 2017) at: https://nplusonemag.com/online-only/online-only/commercial-surveillance-state/

Department of Defense (2003) Information Operations Roadmap. National Security Archive Online, 30 October. Available (accessed 24 August 2015) at: http://www.gwu.edu/ nsarchiv/NSAEBB/ NSAEBB177/info_ops_roadmap.pdf

Deputy Sec. of Defense (2006) QDR Execution Roadmap for Strategic Communication. Available (accessed 20 June 2013) at: http://www.defense.gov/pubs/pdfs/QDRRoadmap20060925a.pdf

Deputy Sec. of Defense (2007a) Memorandum: Policy for DoD Interactive Internet Activities. 8 June. [AQ: 9]

Deputy Sec. of Defense (2007b) Memorandum: Policy for Combatant Command Websites Tailored to Foreign Audiences. 3 August. [AQ: 10]

Dorril S (2002) MI6: Inside the Covert World of Her Majesty's Secret Intelligence Service. New York, NY: Simon and Schuster.

Entman RM (2004) Projections of Power: Framing News, Public Opinion, and US Foreign Policy. Chicago, IL: Chicago University Press.

Esposito JL and Kalin I (2011) Islamophobia: The Challenges of Pluralism in the 21st Century. Oxford: Oxford University Press.

French D (2012) The British Way in Counterinsurgency 1945-1967. Oxford: Oxford University Press.

Gardiner S (2003) Truth from these podia. 8 October. Available (accessed 24 August 2015) at: http://www2. gwu.edu/ nsarchiv/NSAEBB/NSAEBB177/Info\%20Operations\%20Roadmap $\% 20$ Truth $\% 20$ from $\% 20$ These\%20Podia.pdf

Gerth J (2005) Military's information war is vast and often secretive. New York Times. Available (accessed 21 August 2016) at: http://www.nytimes.com/2005/12/11/politics/11propaganda.html?_r=1

Hastedt G (2005) Public intelligence: Leaks as policy instruments-the case of the Iraq war. Intelligence and National Security 20(3): 419-439.

Herman E and Chomsky N (2008) Manufacturing Consent. London: Bodley Head.

Herring E and Robinson P (2014) Deception and Britain's road to war in Iraq. International Journal of Contemporary Iraqi Studies 8(2-3): 213-232.

House of Representatives (2008) Misleading information from the battlefield: The Tillman and Lynch episodes. Report to Congress. Available (accessed 24 August 2015) at: http://www.gpo.gov/fdsys/pkg/ CRPT-110hrpt858/html/CRPT-110hrpt858.htm 
Miller D (2004) Information dominance. Coldtype Press. January. Available (accessed 24 August 2015) at: http://www.coldtype.net/Assets.04/Essays.04/Miller.pdf

Miller D and Sabir R (2012) Counter-terrorism as counterinsurgency in the UK 'war on terror'. In: Poynting $\mathrm{S}$ and Whyte D (eds) Counter-terrorism and State Political Violence: The 'War on Terror' as Terror. London: Routledge, 12-32.

National Priorities Project (2015) How military spending has changed since 9/11. Accessed (accessed 24 September 2017) at: https://www.nationalpriorities.org/campaigns/how-military-spending-has-changed/

NPR (2008) Reminder: Saddam statue was toppled by psy-ops. The Bryant Park Project. Accessed (accessed 10 August 2016) at: http://www.npr.org/templates/story/story.php?storyId=89489923

Papacharissi Z and Oliveira M (2008) Frames on terrorism: A comparative analysis of terrorism coverage in UK and US newspapers. International Journal of Press Politics 13(1): 52-74.

Pew Research Center (2009) Press accuracy rating hits two decade low. 13 September. Accessed (accessed 29 September 2017) at: www.people-press.org/2009/09/13/press-accuracy-rating-hits-two-decade-low/

Schwartz J (2013) Lie after lie after lie: What Colin Powell knew ten years ago today and what he said. Huffington Post. Accessed (accessed 20 September 2017) at: http://www.huffingtonpost.com/jonathanschwarz/colin-powell-wmd-iraq-war_b_2624620.html

Silverberg D and Heimann J (2009) An ever-expanding war: Legal aspects of online strategic communication. Parameters 77-93.[AQ: 11]

Silverstein K (2007) Dorrance Smith's Department of Propaganda: Meet the American 'Baghdad Bob'. Harpers. Available (accessed 21 August 2016) at: harpers.org/blog/2007/07/dorrance-smiths-department-of-propaganda-meet-the-american-baghdad-bob/

Smith-Mundt Act (2012) Available (accessed 25 August 2015) at: http://thomas.loc.gov/cgi-bin/query/ z?c112:H.R.5736

Snow N and Taylor P (2006) The revival of the propaganda state: US propaganda at home and abroad since 9/11. International Communication Gazette 68(5-6): 389-407.

US Senate (2006) Congressional Record: Proceedings and Debates of the 109th Congress, Second Session. 152(pt. 5) 5734.[AQ: 12]

Vanden Brook T (2012) US 'info ops' programs dubious, costly. USA Today. Available (accessed 24 August 2015) at: http://usatoday30.usatoday.com/news/military/story/2012-02-29/afghanistan-iraq-militaryinformation-operations-usa-today-investigation/53295472/1

Vanden Brook T (2013a) Pentagon's information operations chief moves on. USA Today. Available (accessed 21 August 2016) at: http://www.usatoday.com/story/news/politics/2013/08/08/austin-branch-information-operations-pentagon-nctc/2629939/

Vanden Brook T (2013b) White House fights bid to kill Pentagon propaganda sites. USA Today. Available (accessed 29 September 2017) at: https://www.usatoday.com/story/nation/2013/11/19/pentagon-propaganda-web-sites-white-house/3641467/\#

Weiner T (2008) Legacy of Ashes: History of the CIA. London: Penguin.

Woolley SC and Howard PN (2017) Computational propaganda worldwide: Executive summary. Computational Propaganda Project. Available (accessed 24 September 2017) at: http://comprop.oii. ox.ac.uk/wp-content/uploads/sites/89/2017/06/Casestudies-ExecutiveSummary.pdf 